\title{
Cardiopulmonary Changes in the Crying Neonate
}

\author{
ROBERT DINWIDDIE, ROBERT PITCHER-WILMOTT, JACOB G. SCHWARTZ, THOMAS H. \\ SHAFFER, AND WILLIAM W. FOX \\ Divisions of Neonatology and Respiratory. Diseases, The Children's Hospital of Philadelphia and the University of \\ Pennsylvania School of Medicine, and the Department of Physiology. Temple University School of Medicine,
} Philadelphia, Pennsylvania, USA

\begin{abstract}
Summary
To determine hemodynamic effects of crying, 12 newborn infants recovering from the respiratory distress syndrome (RDS) were studied.

When crying, the range of inspiratory esophageal pressure was -18.8 to $-32.5 \mathrm{~cm} \mathrm{H}_{2} \mathrm{O}$ and the range of expiratory pressure was +6.2 to $+34.4 \mathrm{~cm} \mathrm{I}_{2} \mathrm{O}$. The esophageal pressure remained positive for a mean value of $66 \%$ of the respiratory cycle. There was a mean significant increase in heart rate of 19 beats $/ \mathrm{min}$. The systolic and diastolic blood pressures increased significantly at the beginning of strain to 115 and $135 \%$ of the respective control values. There was a progressive decrease in systolic and diastolic pressures during the period of strain and the systolic pressures reached values significantly less than control. With the decrease in systolic and diastolic pressures, there were pronounced reductions in pulse pressures. Three infants reached pulse pressure values less than $1 \%$ of control when cries were sustained for nine cardiac cycles.

There was a significant mean decrease in arterial oxygen tension $\left(\mathrm{PaO}_{2}\right)$ of $16.8 \mathrm{~mm} \mathrm{Hg}$. There were no changes in arterial carbon dioxide tension $\left(\mathrm{PaCO}_{2}\right)$, pH, or base excess.

\section{Speculation}

Asphyxiated neonates and infants with RDS often have a compromised circulation with hypoxemia and hypotension. This study suggests that the circulatory status in such infants may be further compromised by extended periods of crying. In three patients who were relatively stable and normovolemic, a profound decrease in pulse pressure was observed when the cry included seven or more cardiac cycles. These transient periods of no aortic flow might be of clinical significance in critically ill infants. The decreased frequency of crying observed in critically ill neonates may be beneficial to both oxygenation and hemodynamic stability.
\end{abstract}

The newborn infant with mild to moderate RDS is acutely ill during the first few days of life. If adequate support is provided during this period, the infant enters a period of recovery and his pulmonary function gradually improves. The baby's respiratory rate decreases and crying is seen more frequently as grunting respiration disappears.

Previous studies have examined the effect of crying on $\mathrm{PaO}_{2}(5$, $8,13)$, and it has been shown that crying normally produces a decrease in $\mathrm{PaO}_{2}$ approximating $20 \mathrm{~mm} \mathrm{Hg}$ during the first 5 days of life (5). Crying also has significant hemodynamic effects in the newborn and the high intrathoracic pressures generated during the cry make it clinically similar to a Valsalva maneuver as performed by adults.

Previous studies of blood pressure changes in infants have given different results. Young and Holland (16) reported that there was no increase in systolic blood pressure with crying in the first few days of life but Moss et al. (11) reported an increase in systolic and diastolic blood pressure. There have been no reports of sequential changes in blood pressure during prolonged crying cycles in neonates. If neonatal blood pressure exhibited significant variations such as those seen in adults during Valsalva maneuvers, these pressure fluctuations could have clinical significance.

The present study was designed to quantitate the sequential changes in respiration and circulation during crying in newborn infants recovering from RDS.

\section{MATERIALS AND METHODS}

Twelve infants were studied after informed parental consent was obtained. All were recovering from RDS and they all had decreasing oxygen requirements with absence of grunting at the time when the measurements were made. The clinical data of the patients who were studied are shown in Table 1. The mean birth wt was $1.91 \mathrm{~kg}$ (range 1.25-2.67) and the mean gestation was 34 weeks (range 30-38). The mean age at the time of study was $66 \mathrm{hr}$ (range 22-137).

Infants were studied in the supine position under an overhead radiant heater (Air Shields) set to maintain skin temperature at $37^{\circ} \mathrm{C}$. Intraesophageal pressure changes were measured with a soft $2.5 \mathrm{~cm}$ by $0.5 \mathrm{~cm}$ latex balloon attached to the end of a $5 \mathrm{Fr}$ polyvinyl tube placed in the lower third of the esophagus approximately $12 \mathrm{~cm}$ from the gum line. A Statham 23 DC differential pressure transducer was used and pressures were recorded with a multichannel pen recorder (Grass model 5A). The esophageal balloon was calibrated with a water manometer before each study.

Routine monitoring of blood gas tensions and blood pressures was conducted via indwelling umbilical artery catheters, which were placed in the lower aorta. Blood pressures were measured with a strain gauge (Hewlett-Packard model \#1280) and a blood pressure module (Hewlett-Packard model \#78205A). The output was recorded on a multichannel pen recorder simultaneously with the intraesophageal pressure. Respiratory rate was counted visually and heart rate was calculated from the blood pressure recordings. Beat to beat variations in blood pressure were also evaluated. Blood gas determinations were made on $0.5 \mathrm{ml}$ samples of heparinized blood which were drawn from the arterial lines, stored on ice, and analyzed within 15 min using standard blood gas apparatus (Instrumentation Laboratories, model \#113 and 213). Base excess values were derived from the Siggaard-Anderson nomogram (14). Inspired oxygen concentration ( $\left.\mathrm{FiO}_{2}\right)$ was measured with a paramagnetic oxygen analyzer (Beckman, type Fl, Beckman Laboratories, Palo Alto, CA) as each blood gas sample was drawn.

Each infant was studied twice; initially while resting quietly to obtain control data, and then after $1 \frac{1}{2}$ min of vigorous crying which was induced by stimulating the heel. Three separate cries were selected for each infant to calculate the hemodynamic data using cries which were the most typical for shape and amplitude of pressure changes. Statistical analysis was performed by Student's paired $t$ test. 


\section{RESULTS}

Figure 1 demonstrates traces obtained from a period of quiet respiration and during a typical cry. There was a short, rapid inspiration with negative esophageal pressure followed by a longer period of expiration when the esophageal pressure was positive. The mean peak negative pressure during inspiration for all patients was $-24.1 \mathrm{~cm} \mathrm{H}_{2} \mathrm{O}$ (range -18.8 to -32.5 ). The mean peak positive pressure for all patients was $+18.0 \mathrm{~cm} \mathrm{H}_{2} \mathrm{O}$ (range +6.2 to +34.4 ). The esophageal pressure remained positive for a mean value of $66 \%$ of the respiratory cycle and showed large variations during crying similar to those seen in adults performing a Valsalva maneuver. The results of the physiologic measurements are shown in Table 2. As expected, respiratory rate decreased during crying and was associated with a significant increase in heart rate with a mean change of 19 beats/min. The blood pressure values (up to nine heartbeats per cry) observed throughout the whole of the positive pressure phase showed no change in mean systolic blood pressure, but there was a significant increase of $9 \mathrm{~mm} \mathrm{Hg}$ in the mean diastolic blood pressure with a corresponding significant decrease of $6 \mathrm{~mm} \mathrm{Hg}$ in the mean pulse pressure. In association with the hemodynamic changes that occurred there was a significant decrease of $16.8 \mathrm{~mm} \mathrm{Hg}$ in the mean $\mathrm{PaO}_{2}$. There were no significant changes in mean $\mathrm{PaCO}_{2}, \mathrm{pH}$, or base excess.

In order to document the sequential changes during expiration, blood pressure was examined in successive heartbeats during the positive pressure phase of each sustained cry. Figure 2 shows the changes; there were initial significant increases $(P<0.001)$ in both systolic and diastolic blood pressures, but after the second heartbeat, the systolic and diastolic pressures decreased progressively towards control values. By the seventh beat, the systolic pressure was significantly less than the control systolic pressure $(P<0.05)$ whereas the diastolic pressure was similar to its control value. In the three patients who sustained a cry for longer than seven cardiac cycles, there were secondary rises in both systolic and diastolic pressures. Due to the small number of observations, it was difficult to demonstrate statistical significance, but these changes correspond to those seen in phase two of a Valsalva maneuver.

Figure 3 demonstrates the reduction in pulse pressure that occurred with each successive heartbeat during a cry. These pressures were all significantly reduced compared to control values. Only three patients had cries which included as many as nine heartbeats, but in these infants, the pulse pressure by the ninth heartbeat was so low (less than $1 \%$ control value) that blood flow had virtually ceased.

\section{DISCUSSION}

This study demonstrates that large and rapid fluctuations in intrathoracic and arterial pressure occur during crying in infants recovering from RDS and that these correspond in many ways to those seen in adults during a Valsalva maneuver.

A typical cry lasted several seconds and consisted of an initial gasp with large negative intraesophageal pressures. During the expiratory part of the cry, the pressure increased by as much as 60 $\mathrm{cm} \mathrm{H}_{2} \mathrm{O}$ resulting in profound effects on pulse pressure. These extremes of pressure require considerable muscular force and in fact, the work of breathing of a cry in infants of this age is similar to the total work of the first breath (1). The esophageal pressure

Table 1. Clinical data

\begin{tabular}{|c|c|c|c|c|c|}
\hline Case no. & Sex & Birth weight $(\mathrm{kg})$ & $\begin{array}{l}\text { Gestational age } \\
\text { (wk) }\end{array}$ & Age studied (hr) & Comments \\
\hline 1 & $\mathbf{M}$ & 1.36 & 32 & 30 & Survived \\
\hline 2 & $\mathbf{M}$ & 1.97 & 33 & 37 & Survived \\
\hline 3 & $\mathbf{M}$ & 2.40 & 35 & 77 & Survived \\
\hline 4 & $\mathbf{M}$ & 1.28 & 30 & 48 & $\begin{array}{l}\text { Died, aged } 28 \text { days. Necrotizing en- } \\
\text { terocolitis. }\end{array}$ \\
\hline 5 & M & 1.69 & 32 & 82 & Survived \\
\hline 6 & M & 1.88 & 33 & 137 & Survived \\
\hline 7 & $\mathbf{M}$ & 2.10 & 33 & 105 & Survived \\
\hline 8 & $\mathrm{~F}$ & 2.67 & 37 & 120 & Survived \\
\hline 9 & $\mathbf{M}$ & 1.86 & 33 & 23 & $\begin{array}{l}\text { Died, aged } 10 \text { days. Necrotizing en- } \\
\text { terocolitis. }\end{array}$ \\
\hline 10 & M & 1.25 & 33 & 22 & Survived \\
\hline 11 & M & 2.30 & 38 & 78 & Survived \\
\hline 12 & $\mathbf{M}$ & 2.20 & 36 & 35 & Survived \\
\hline Mean & & 1.91 & 33.75 & 66 & \\
\hline
\end{tabular}
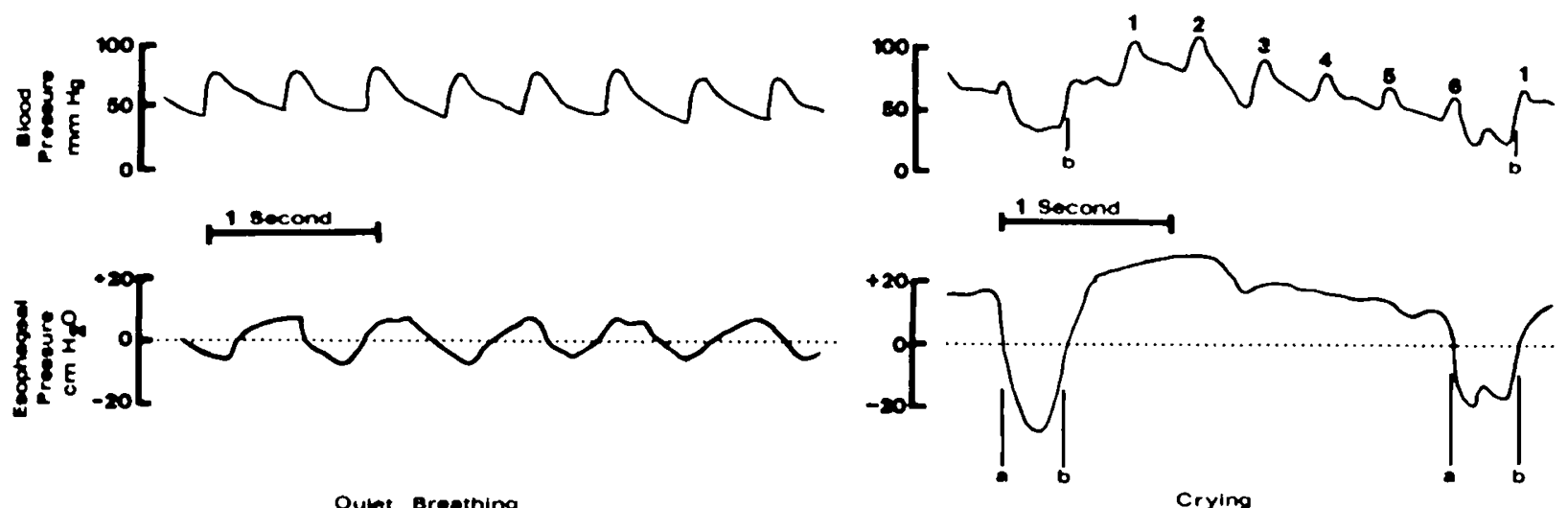

Qubet Bresthing

Crying

Fig. 1. Abdominal aortic pressure and esophageal pressure during quiet breathing and crying. For the crying portion $a$ shows the beginning of the inspiratory gasp, $b$ shows the start of the positive pressure, expiratory part of the cry. The heart beat numbers are shown. 
Table 2. Changes in physiologic parameters in crying ${ }^{1}$

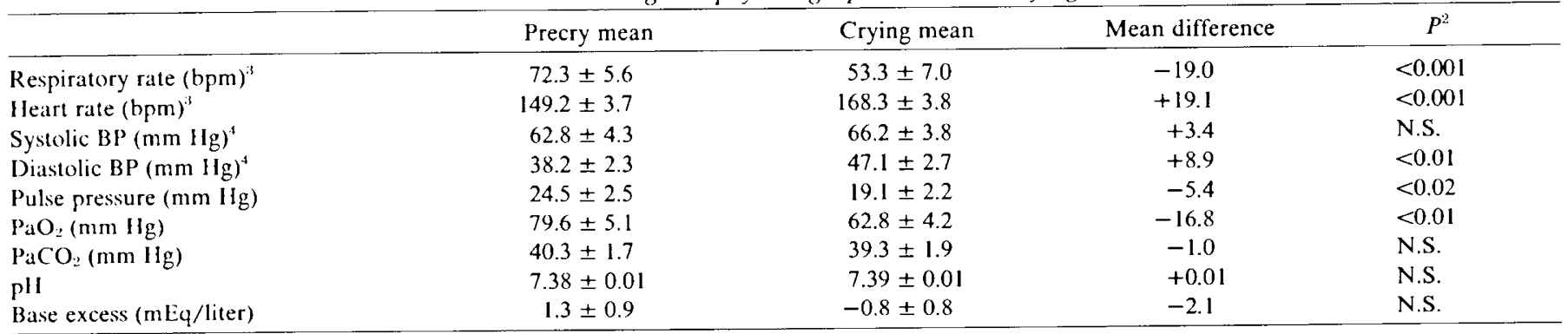

' Data derived from 12 patients and shown as mean $\pm \mathrm{SE}$.

"Tested for statistical significance with Student's paired $t$ test.

${ }^{3}$ Beats per minute.

${ }^{4}$ Blood pressure.

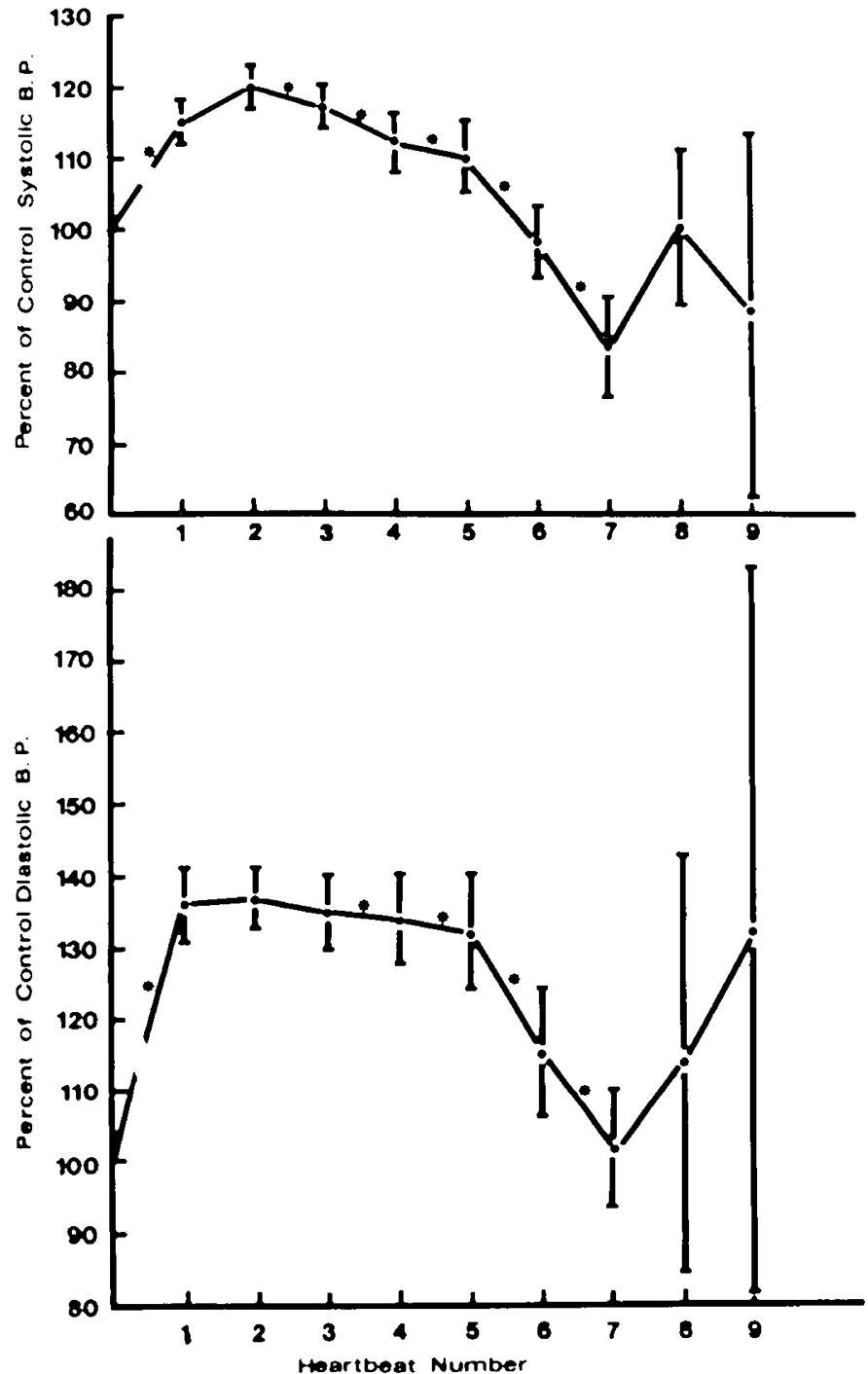

Fig. 2. Progressive changes in mean \pm SEM systolic and diastolic blood pressures during sustained cries analyzed in relation to successive heart beats during the cry. The data were derived from three cries in each of the 12 infants and the mean values are shown as percent of the respective control values. ${ }^{*}$ represents a statistically significant difference $(P<0.05)$ between adjacent heart beats by paired $t$ testing.

swings during periods of quiet respirations were in the range of 5 $10 \mathrm{~cm} \mathrm{H}_{2} \mathrm{O}$ which is in the range reported in similar neonates $(9$, 12).

The patterns of blood pressure changes which occurred in crying neonates are similar to those reported during a Valsalva maneuver

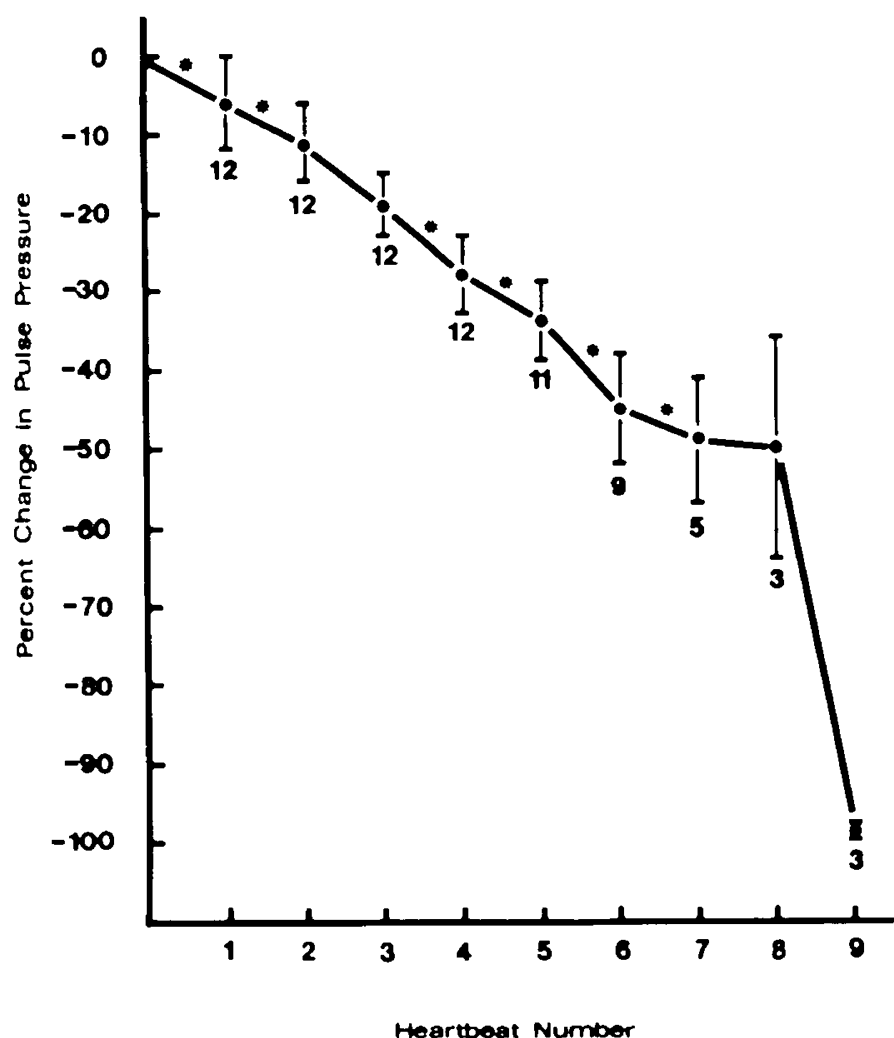

Fig. 3. The effect of sustained cries on mean \pm SEM percent change in pulse pressure analyzed in relation to successive heart beats during the cry. The number of patients is shown for each point. ${ }^{*}$ represents a statistically significant difference $(P<0.05)$ between adjacent points by paired $t$ testing.

in adults $(7,15)$. There were initial increases in both systolic and diastolic pressures which correspond to phase 1 of the Valsalva maneuver (7). Then there were progressive decreases in both systolic and diastolic blood pressures and marked reductions in pulse pressures; these changes correspond to phase 2 of the Valsalva maneuver. The changes in phase 1 are related to an increased venous return during the preceding gasp and the transmission of positive intrathoracic pressure to the heart and great vessels during strain $(4,15)$. Phase 2 ensues when venous return decreases due to a raised intrathoracic pressure. A recent investigation using ventriculography showed that stroke volume decreases by nearly $50 \%$ in adults during this phase (3). This corresponds to the dramatic fall in pulse pressure which we observed. Because the infants in our study were evaluated during uninterrupted successive cries, it was not possible to identify phases 3 and 4 of the maneuver. A secondary rise in blood pressure was observed in three patients during the positive expiratory part of the cry. It is possible that 
this corresponds to the secondary rise of phase 2 . This has been described in adults performing the Valsalva maneuver and is the result of reflex vasoconstriction and tachycardia (15).

The current investigation demonstrates that blood pressure changes vary in direction at different times during a prolonged cry, which may explain the discrepancies between previous reports on the effect of crying on neonatal arterial pressure. The mean systolic pressure over the whole cry did not change because the mean value from several heartbeats averages out the rise in systolic blood pressure at the beginning of strain and gradual decline which follows. This might explain the finding by Young and Holland (16) that there was no effect of crying on systolic blood pressure measured during the first 3 days of life. The authors' observations agree with those of Moss et al. (11) who reported an increase in both systolic and diastolic blood pressures during crying, using direct measurements via the umbilical artery. They analyzed the maximum values that were reached during a cry and these values correspond to the initial increase in systolic and diastolic pressures that we observed. Similar results were obtained in the study by Gupta and Scopes (6) in infants with a wide range of clinical problems studied during the first day of life, although they did not describe the exact point in the cry at which blood pressure was determined.

The effect of crying on arterial oxygenation has been studied previously $(5,8,13)$. The current investigation confirms the decrease in $\mathrm{PaO}_{2}$ which has been observed and which probably results from an increase in right-to-left shunting. This may occur in one of the three ways; first, at the atrial level when it is likely to be the result of increased atrial filling after the preceding inspiration $(2,10)$. Second, right-to-left shunting may occur from ventilation-perfusion imbalance during the expiratory portion of the cry. Third, ductal shunting would increase during crying because of increased pulmonary artery pressure that occurs with a forced expiration (15).

\section{REFERENCES AND NOTES}

1. Avery. M. E.. and Fletcher. B. D.: In: The Lung and its Disorders in the Newborn Infant. 3rd edition, p. 34 (W. B. Saunders Co., Philadelphia, 1974).

2. Brecher, D. F., and Opdyke, D. F.: Effects of normal and abnormal respiration on hemodynamics of experimental interatrial septal defects. Am. J. Physiol., 162: 507 (1960).

3. Brooker, J. Z., Alderman, E. L., and Harrison, D. C.: Alterations in left ventricular volumes induced by Valsalva maneuver. Br. Heart J., 36: 713 (1974).

4. Burnard. E. D., and James, L. S.: The cardiac silhouette in newborn infants. A cinematographic study of the normal range. Pediatrics, 27: 713 (1961)

5. Dinwiddie, R., Kumar, S. P., Patel, B. D., and Fox, W. W.: Transient hypoxemia in the crying neonate recovering from the respiratory distress syndrome Pediatr. Res., 10: 460 (1976)

6. Gupta, J. M., and Scopes, J. W.: Observations on blood pressure in newborn infants. Arch. Dis. Child., 40:637 (1965)

7. Hamilton, W. F., Woodburg, R. A., and Harper. M. T.: Physiologic relationships between intrathoracic, intraspinal and arterial pressures. J.A.M.A., 107: 853 (1936)

8. Harrison, V. C.. Heese, H. de V., and Klein, M.: The significance of grunting in hyaline membrane disease. Pediatrics, 4I: 549 (1968).

9. Kreiger. I.: Studies on mechanics of respiration in infancy. Am. J. Dis. Childhood, 105: 439 (1963).

10. Lind, J., Stern, L., and Wegelius, C.: In: Human Fetal and Neonatal Circulation. p. 39 (Thomas, Springfield, IL, 1964)

11. Moss, A. J., Duffie. E. R., and Emmanouilides, G.: Blood pressure and vasomotor reflexes in the newborn infant. Pediatrics, 32: 175 (1963).

12. Patel. B. D., Dinwiddie, R., Kumar, S. P., and Fox, W. W.: The effects of feeding on arterial blood gases and lung mechanics in newborn infants recovering from respiratory disease. J. Pediatr., 90: 435 (1977)

13. Prec, K. J., and Cassels, D. E.: Oximeter studies in newborn infants during crying. Pediatrics, 9: 756 (1962).

14. Siggaard-Anderson, O.: Blood acid-base alignment nomogram. Scand. J. Clin. Lab. Invest., 15: 1 (1963).

15. Stone, D. J., Lyon, A. F., and Teirstein. A. S.: A reappraisal of the circulatory effects of the Valsalva maneuver. Am. J. Med., 39: 923 (1965).

16. Young. I. M. and Holland, W. W.: Some physiological responses of neonatal arterial blood pressure and pulse rate. Br. Med. J., 2: 276 (1958).

17. Requests for reprints should be addressed to: William W. Fox. M.D., Division of Neonatology. The Children`s Hospital of Philadelphia, 34th Street \& Civic Center Boulevard, Philadelphia, PA 19104, USA.

18. Received for publication May 26, 1978.

19. Accepted for publication July 27,1978 